\title{
Biosynthesis of silver nanoparticles from the marine seaweed Sargassum wightii and their antibacterial activity against some human pathogens
}

\author{
N. Shanmugam $\cdot$ P. Rajkamal $\cdot$ S. Cholan $\cdot$ \\ N. Kannadasan · K. Sathishkumar • \\ G. Viruthagiri $\cdot$ A. Sundaramanickam
}

Received: 15 August 2013/Accepted: 10 September 2013/Published online: 26 September 2013

(C) The Author(s) 2013. This article is published with open access at Springerlink.com

\begin{abstract}
In this paper, we have reported on biological synthesis of nano-sized silver and its antibacterial activity against human pathogens. The nanoparticles of silver were formed by the reduction of silver nitrate to aqueous silver metal ions during exposure to the extract of marine seaweed Sargassum wightii. The optical properties of the obtained silver nanoparticles were characterized using UV-visible absorption and room temperature photoluminescence. The $\mathrm{X}$-ray diffraction results reveal that the synthesized silver nanoparticles are in the cubic phase. The existence of functional groups was identified using Fourier transform infrared spectroscopy. The morphology and size of the synthesized particles were studied with atomic force microscope and highresolution transmission electron microscope measurements. The synthesized nanoparticles have an effective antibacterial activity against $S$. aureus, $K$. pneumoniae, and S. typhi.
\end{abstract}

Keywords Ag nanoparticles - Sargassum wightii . Antibacterial activity $\cdot$ Cubic phase $\cdot$ AFM

\section{Introduction}

In recent years the nanoparticles have consumed ample space in the field of marine bio-nanotechnology. It is believed that nanoparticles are clusters of atoms in the size range of

N. Shanmugam $(\bowtie) \cdot$ P. Rajkamal · S. Cholan .

N. Kannadasan · K. Sathishkumar · G. Viruthagiri

Department of Physics, Annamalai University, Annamalai

Nagar, Chidambaram 608 002, Tamilnadu, India

e-mail: quantumgosh@rediffmail.com

A. Sundaramanickam

CAS in Marine Biology, Faculty of Marine Sciences, Annamalai

University, Parangipettai, Tamil Nadu, India
1-100 nm (Williams 2008). Nanoparticles are classified primarily into two types, viz organic and inorganic nanoparticles. The nanoparticles of carbon are called the organic nanoparticles. Magnetic nanoparticles, noble metal nanoparticles (platinum, gold and silver) and semiconductor nanoparticles (titanium dioxide, zinc oxide and zinc sulfide) are classified as inorganic nanoparticles (Kathiresan and Asmathunisha 2013). The metal nanoparticles have magnetic, electronic and optical properties, which make their usage in different fields like medicine, agriculture and electronics (Rai et al. 2012). Among the metal nanoparticles, silver nanoparticles have gained remarkable consideration owing to their physicochemical properties (Elechiguerra et al. 2005).

Nanoparticles of silver are widely used in water filters (Jain and Pradeep 2005), bio sensors (Chen et al. 2007), antibacterial activity (Venkatpurwar and Pokharkar 2011), anti-HIV activity (Elechiguerra et al. 2005) and in controlling plant pathogens (Krishnaraj et al. 2012). The biosynthetic method employing marine seaweed extract has received more attention as being simple, eco-friendly and less time consuming compared to usual chemical and physical methods.

In the present study, the extracellular synthesis of silver nanoparticles by the brown seaweed Sargassum wightii and their antibacterial effects against some selected human pathogens are reported.

\section{Materials and methods}

Sample collection

The green seaweed $S$. wightii was collected from Mandapam costal region $\left(78^{\circ} 8^{\prime} \mathrm{E}, 9^{\circ} 17^{\prime} \mathrm{N}\right)$ in Gulf of manner, the southeast coast of India. Immediately after the collection, the 
samples were transferred to the laboratory in new plastic bags containing natural sea water to prevent desiccation.

\section{Materials}

Silver nitrate $\left(\mathrm{AgNO}_{3}\right)$ was purchased from Merck. The glass wares used in this experimental work were acid washed. Ultrapure water was used for all dilution and sample preparation.

Preparation of seaweeds extract

The seaweed was washed thoroughly thrice with distilled water and was shade dried for 10 days. Fine powder of the seaweed was obtained by using kitchen blender. The seaweed powder was sterilized at $120^{\circ} \mathrm{C}$ for $15 \mathrm{~min}, 20 \mathrm{~g}$ of powder was taken and mixed with $100 \mathrm{ml}$ of milli Q water and kept in boiling water bath at $60{ }^{\circ} \mathrm{C}$ for $20 \mathrm{~min}$. The extracts were filtered with Whatman No. 1 filter paper and stored in refrigerator at $4{ }^{\circ} \mathrm{C}$ for further studies.

Synthesis of AgNPs

For the biosynthesis of silver nanoparticles, $5 \mathrm{ml}$ of seaweed extract was mixed with $50 \mathrm{ml}$ of $\mathrm{AgNO}_{3}$ solution and incubated at $28{ }^{\circ} \mathrm{C}$ for $24 \mathrm{~h}$. The bio-reduction of $\mathrm{AgNO}_{3}$ into AgNps can be confirmed visually by the change in color from colorless to reddish brown (Fig. 1).

\section{Characterization techniques}

Characterization of nanoparticles is important to understand and control nanoparticles synthesis and applications (Al-Warthan et al. 2010). The formation of AgNPs was confirmed by sampling the reaction mixture at regular intervals and the absorption maximum was scanned by UV-visible spectra, in a range of wavelength between 400 and $550 \mathrm{~nm}$ using LAMDA 25 PERKIN ELMER spectrometer. The X-ray diffraction (XRD) patterns of the silver nanoparticles were recorded using X'PERT PRO diffractometer with $\mathrm{Cu}-\mathrm{K} \alpha$ radiation $(\lambda=1.5406 \AA)$. The crystallite size was estimated using the Scherer equation. Fluorescence measurements of the synthesized products with different incubation time were carried out using VARIAN Spectrometer. The presence of functional groups in seaweed extract and synthesized AgNPs was identified by SHIMADZU-8400 FTIR Spectrometer using KBr pellet technique. The morphology of the product was observed by Nano Surf Easy Scan 2 Atomic Force Microscope (AFM) measurement. High-resolution transmission electron microscopy (HRTEM) analysis was performed using JEDL 3010 HRTEM to study the morphology and size of the Ag nanoparticles.

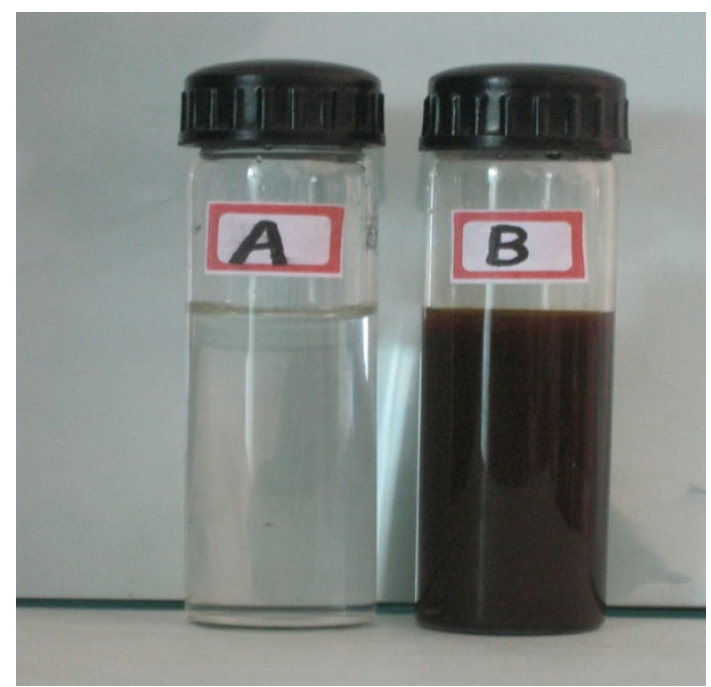

Fig. $1 A$ Silver nitrate $\left(\mathrm{AgNO}_{3}\right)$ solution and $B$ color change during the reduction of $\mathrm{AgNO}_{3}$ into AgNPs by the extract of $S$. wightii after $24 \mathrm{~h}$ of incubation

\section{Antibacterial activity}

Silver is known for its antibacterial properties and has been used for years in the medical field for antimicrobial applications and even has shown to prevent HIV binding to host cells (Nino-Martinez et al. 2008; Alt et al. 2004; Russel and Hugo 1994; Lee et al. 2007; Jeong et al. 2005). In addition, silver has been used in water and air filters to eliminate microorganisms (Chou et al. 2005, Jin et al. 2007). In the present work, the synthesized $\mathrm{Ag}$ nanoparticles in aqueous were tested against bacterial pathogens by agar disc diffraction method (Karting et al. 1991). The pathogens namely $P$. aeruginosa, $V$. cholerae, $K$. pneumoniae, $S$. aureus, E. coli, $S$. pneumoniae and $S$. typhi were obtained from Raja Sir Muthaiya Medical College, Annamalai University. About $150 \mathrm{CFU} / \mathrm{ml}$ of inoculums was swabbed onto $\mathrm{MH}$-agar plates uniformly and allowed to dry in a sterile environment. Sterile disc of $6 \mathrm{~mm}$ (HIMEDIA) were loaded with $30 \mu \mathrm{l}$ of test solution $\left(\mathrm{AgNO}_{3}\right.$ and $\mathrm{Ag}$ nanoparticles). Ampicillin (10 mg in $1 \mathrm{ml})$ was used as positive control. The plates were incubated at $25^{\circ} \mathrm{C}$ for 3 days to measure zone of inhibition. The mean was calculated by performing the experiments in triplicates.

\section{Results and discussion}

Crystal structure analysis and determination of crystallite size

Figure 2 shows the XRD pattern of silver nanoparticles synthesized after $120 \mathrm{~h}$ of incubation. The pattern has three main diffraction features corresponding to (1 111$),\left(\begin{array}{lll}2 & 0 & 0\end{array}\right)$ and 


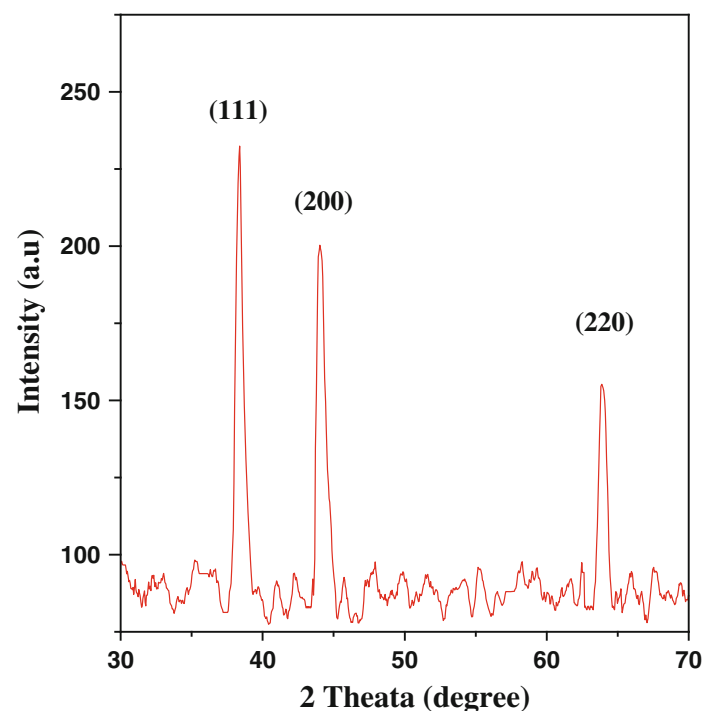

Fig. 2 XRD patterns of silver nanoparticles synthesized after $120 \mathrm{~h}$ of incubation

(2 2 0) planes and all the three peaks can be indexed to standard cubic phase of silver (JCPDS card No 04-0783). No reflection peaks corresponding to nitrate ions and other impurities were noted in this pattern, indicating the high purity of the final product. Moreover, the obtained reflections are sharp and high in intensity which reveals that the synthesized nanoparticles are well crystalline. In addition, the lattice constant of the synthesized cubic phase of silver is found to be ' $a=4.083 \AA$ '. This value is consistent with the JCPDS value ( $a=4.086 \AA$ ). The size of the nanocrystals was determined from the Debye-Scherrer formula $D=0.9 \lambda / \beta \cos \theta$, where $D$ is the crystallite size, $\lambda$ is the wavelength of the incident X-ray (1.5406 $\AA$ ), $\theta$ is the Bragg's angle and $\beta$ is the full width at half maximum (FWHM). From the X-ray line broadening the crystallite size of the synthesized products is estimated around $17 \mathrm{~nm}$ $(r= \pm 10 \%)$.

\section{Optical absorption studies}

The optical properties of metallic nanoparticles depend on its surface plasmon resonance, where the plasmon refers to the collective oscillation of the free electrons within the metallic nanoparticles. It is obviously known that the plasmon resonant peaks and line widths are sensitive to the size and shape of the nanoparticles, the metallic species and the surrounding medium.

UV-visible absorption is one among the most important techniques to identify the formation of metal nanoparticles, provided surface plasmon resonance exists for metal (Binupriya et al. 2010). Figure 3 shows the UV-Vis absorption spectra of reaction mixtures studied at different levels of incubation time (24, 48, 72, 96 and 120 h). From

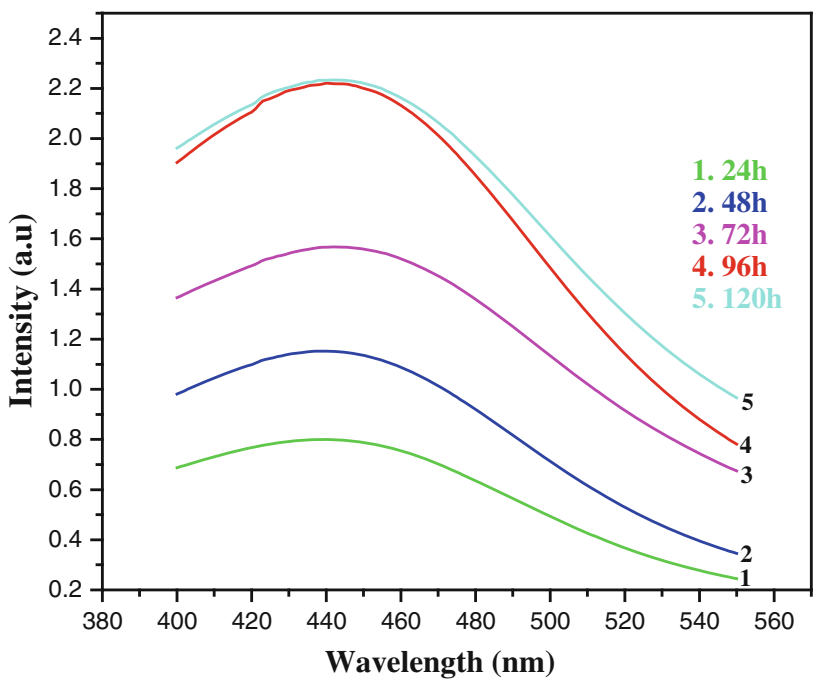

Fig. 3 UV-visible absorption spectra of silver nanoparticles with different incubation time

the absorption spectra, it is noted that Ag surface plasmon resonance band occurs at about $439 \mathrm{~nm}$ and the intensity of absorption increases steadily as a function of incubation time. The interaction of electromagnetic radiation having wavelength smaller than the size of the Ag nanoparticles leads to polarization of the free conduction electrons with respect to the much heavier ionic core of Ag nanoparticles. Therefore, an electron dipolar orientation is set up and resulted in surface plasmon absorption band. The maximum absorption of $441 \mathrm{~nm}$ was obtained for the mixture with the incubation time of $120 \mathrm{~h}$. The red shift of $2 \mathrm{~nm}$ may reduce the band gap and result in increased size of $\mathrm{Ag}$ nanoparticles.

The photoluminescence of silver metal and that of noble metal is generally attributed to electronic transition between the upper $\mathrm{d}$ band and conduction SP band (He et al. 2001). Room temperature PL of Ag nanoparticles was recorded using an excitation wavelength of $325 \mathrm{~nm}$. As shown in Fig. 4, a broad emission peaking at $449 \mathrm{~nm}$ is observed in the emission spectrum due to metal-ligand charge transfer absorption (Xu et al. 2006). Furthermore, the intensity of the emission peak increases with increase of reaction time with a small red shift in peak position. This indicates that the concentration of silver increases with reaction time.

Functional group analysis

To understand the existence of different functional groups responsible for the bio-reduction of $\mathrm{AgNO}_{3}$ into $\mathrm{Ag}$ Nanoparticles, FTIR studies were carried out for $S$. wightii and synthesized silver nanoparticles (Fig. 5a, b). As shown in Fig. 5a, FTIR spectrum of seaweed shows 


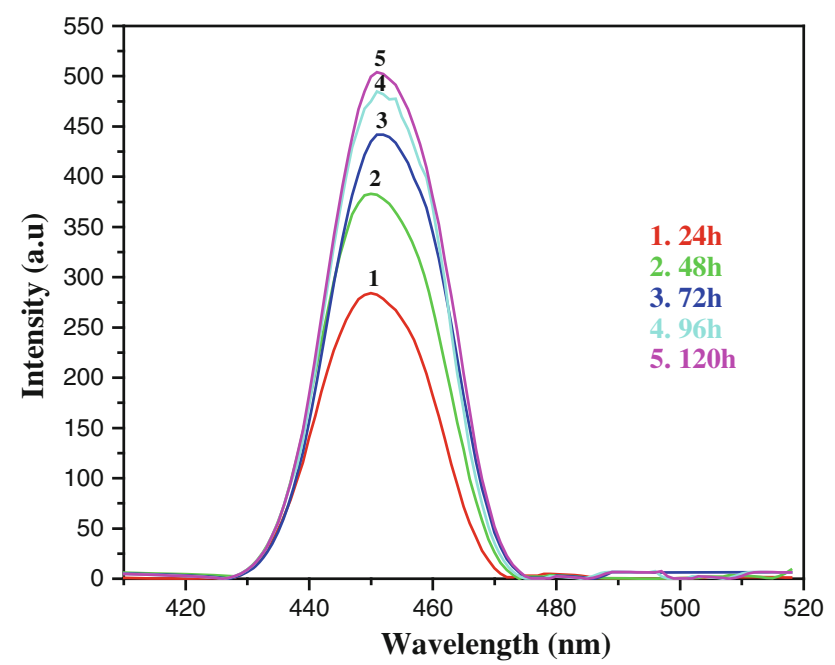

Fig. 4 PL emission spectra of silver nanoparticles with different incubation time

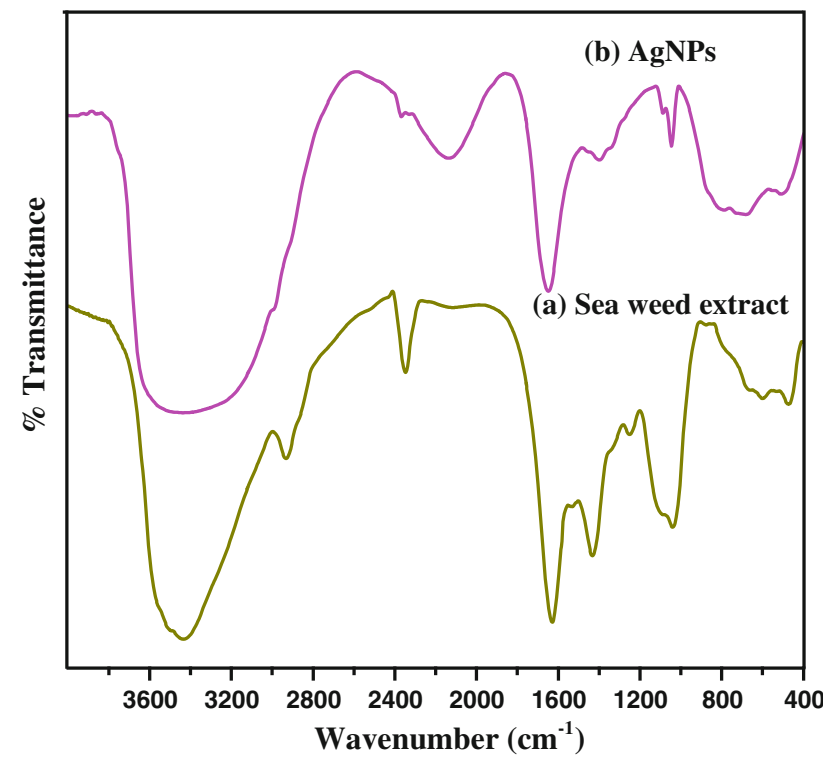

Fig. 5 FTIR spectra of $a$ seaweed extract and $b$ silver nanoparticles (AgNPs)

different major peaks positioned at 3,433, 2,931, 1,630, $1,087,1,032,661,599$ and $468 \mathrm{~cm}^{-1}$. The presence of peak at $3,433 \mathrm{~cm}^{-1}$ could be due to $\mathrm{O}-\mathrm{H}$ group in polyphenols or proteins/enzymes or polysaccharide (Song et al. 2009; Li et al. 2007; Susanto et al. 2009). A small peak observed at $2,931 \mathrm{~cm}^{-1}$ is due to $\mathrm{CH}$-stretching of alkanes. A sharp and intense band observed at $1,630 \mathrm{~cm}^{-1}$ may be ascribed to the stretching vibration of the $(\mathrm{NH})=\mathrm{O}$ group. The bands positioned at 1,087 and $1,032 \mathrm{~cm}^{-1}$ are due to $\mathrm{C}-\mathrm{N}$ stretching vibration of aliphatic amines. The observed bands ranging between 661 and $468 \mathrm{~cm}^{-1}$ are due to $\alpha$-glucopyranose rings deformation of carbohydrates (Yang et al. 2009). On the other hand, FTIR spectrum of synthesized Ag nanoparticles (Fig. 5b) shows the presence of major peaks at 3,435, 2,931, 1,649, 1,085, 1,045 , and $680 \mathrm{~cm}^{-1}$ which are associated with $-\mathrm{OH}$ stretching vibrations, $\mathrm{C}-\mathrm{H}$ of alkanes, amide 1 band of proteins, $\mathrm{C}-\mathrm{N}$ stretching vibration of amines, $\mathrm{C}-\mathrm{N}$ stretching vibration of aliphatic amines and $\alpha$-glucopyranose rings deformation of carbohydrates, respectively. After bio-reduction, there is a shift in the absorption band of $1,630-1,649 \mathrm{~cm}^{-1}, \quad 1,087-1,085 \mathrm{~cm}^{-1}$ and $1,032-1,045 \mathrm{~cm}^{-1}$. The shifting of the band from 1,630 to $1,649 \mathrm{~cm}^{-1}$ may be due to the binding of $(\mathrm{NH}) \mathrm{C}=\mathrm{O}$ group with the nanoparticles. The $(\mathrm{NH}) \mathrm{C}=\mathrm{O}$ groups within the cage of cyclic peptides are involved in stabilizing the nanoparticles. Thus, the peptides may play an important role in the reduction of $\mathrm{AgNO}_{3}$ into $\mathrm{Ag}$ nanoparticles. The above-mentioned shift was observed in codium capitatum (Kannan et al. 2013).

\section{Particles morphology (AFM and HRTEM} measurements)

The surface morphology and size of the Ag nanoparticles harvested after $120 \mathrm{~h}$ of incubation were studied by AFM. The two- and three-dimensional images of the nanoparticles are shown in Fig. 6a, b. From the 2D view, well-separated spherical particles are seen. The sizes of the particles are in the range of 5-22 nm. However, most of the particles are in the range of $18 \mathrm{~nm}$. The 3D view revealed that the growth direction of all the particles was almost same.

To confirm, the morphology of the synthesized nanoparticles, HRTEM image was recorded. Figure 7a shows the HRTEM image of the sample synthesized at $120 \mathrm{~h}$ of incubation, revealing the formation of almost monodispersed nanoparticles with average diameter $\sim 2 \mathrm{~nm}$. The TEM image shown in Fig. $7 \mathrm{~b}$ depicts the formation of well-defined spherical nanoparticles with sizes from 15 to $20 \mathrm{~nm}$. The particles size measured from TEM images matches well with the values arrived from the corresponding XRD pattern and AFM measurements. Figure $7 \mathrm{c}$ shows the selected-area electron diffraction (SAED) pattern of the sample. The SAED pattern shows the well-defined electron diffraction spots, confirming the single crystalline nature of the cubic phase of $\mathrm{Ag}$ nanoparticles.

\section{Antibacterial activity}

The antibacterial activity of the bio-synthesized $\mathrm{Ag}$ nanoparticles against different human pathogens is shown 

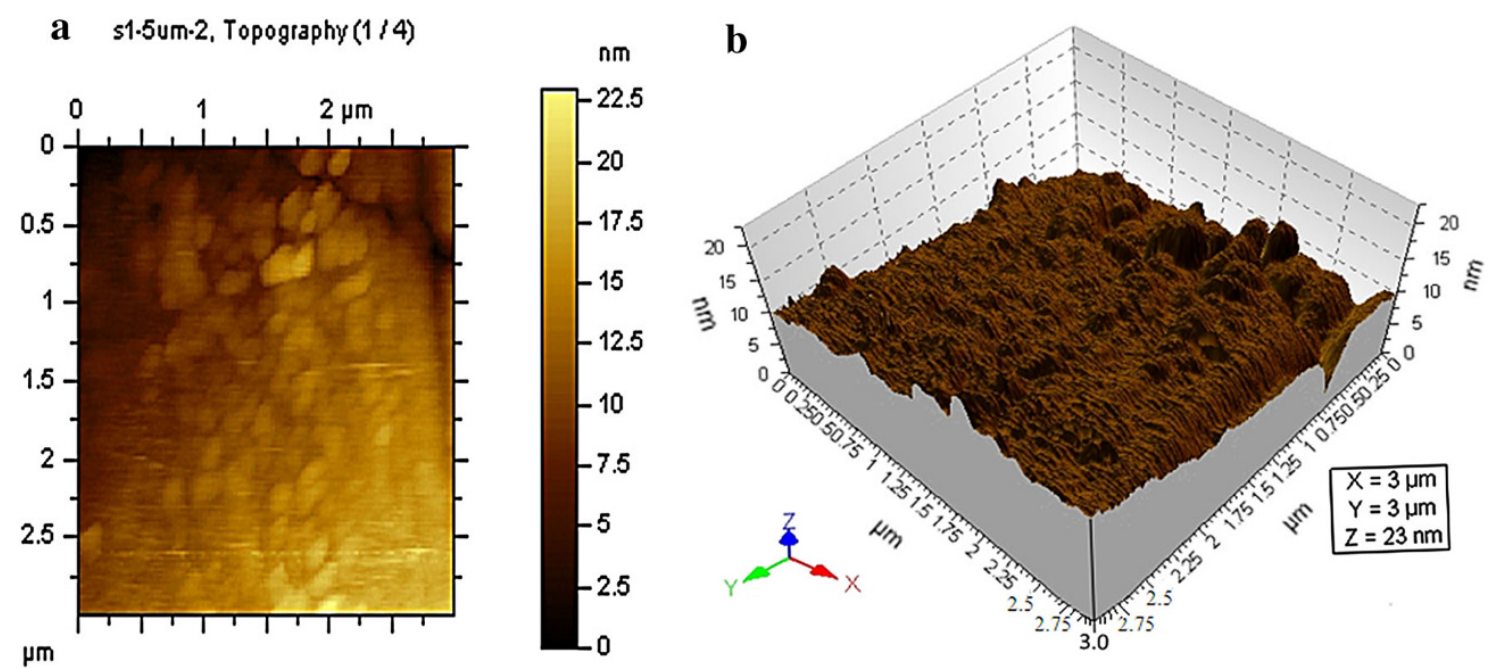

Fig. 6 a AFM images of synthesized silver nanoparticles using extract of Sargassum wightii and b corresponding 3D view
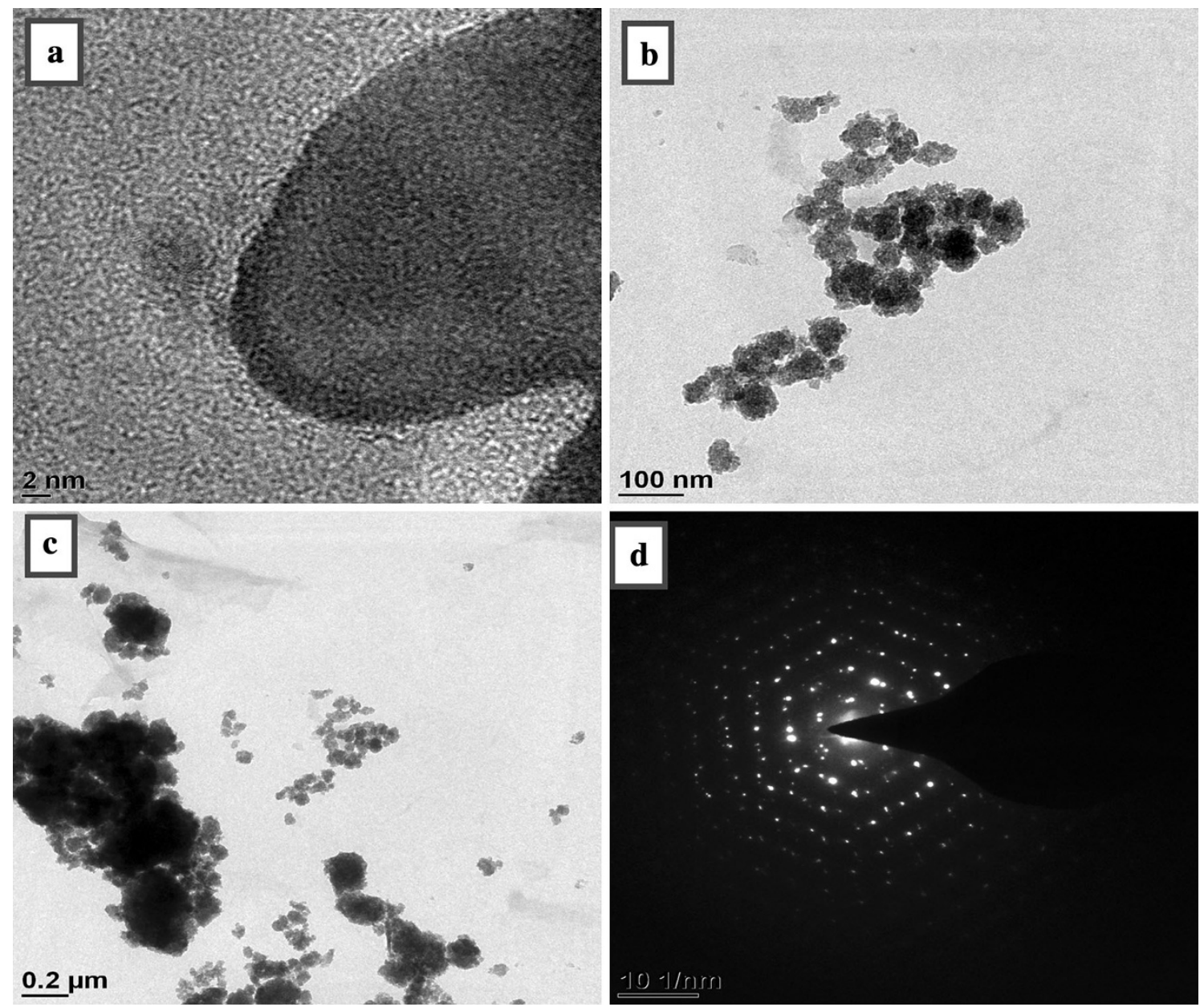

Fig. 7 TEM images of synthesized silver nanoparticles using extract of Sargassum wightii. a HRTEM, b, $\mathbf{c}$ TEM images and d corresponding SAED pattern

in Fig. 8. It is apparent that the $\mathrm{Ag}$ nanoparticles showed inhibition zone against almost all the test organisms (Table 1). Maximum zone of inhibition was found against gram positive $S$. aureus $(12 \mathrm{~mm})$ and it was higher than that of the positive control ampicillin $(6 \mathrm{~mm})$, and minimum zone of inhibition was obtained against

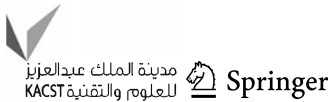



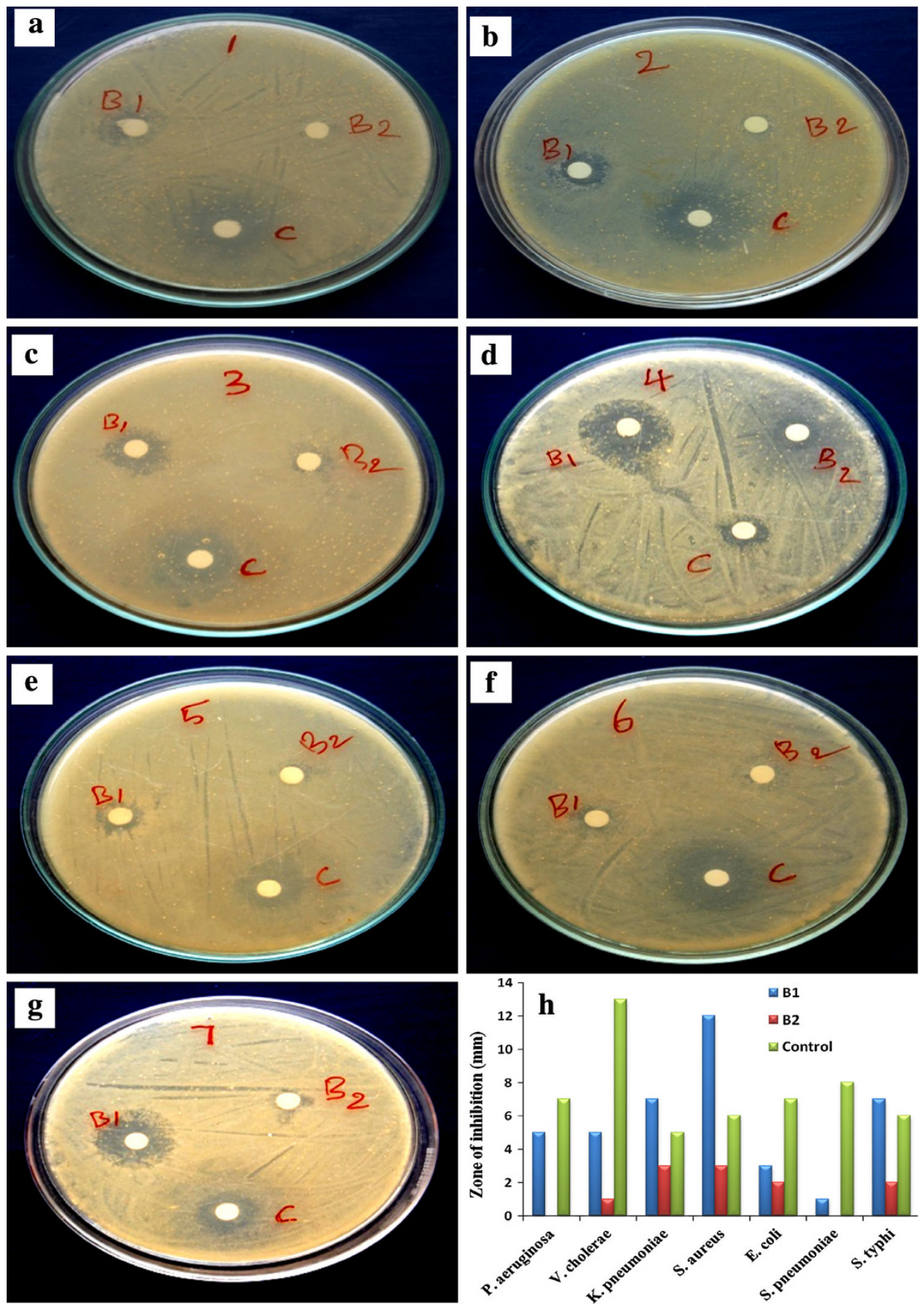

Fig. 8 Antibacterial activity of synthesized silver nanoparticles against a P. aeruginosa, b V. cholerae, c K. pneumoniae, d S. aureus, e E. coli, f $S$. pneumoniae, $\mathbf{g}$ S. typhi and $\mathbf{h}$ corresponding bar diagram

$S$. pneumoniae $(1 \mathrm{~mm})$. Similarly, the gram negative bacteria $S$. typhi also showed higher zone of inhibition $(7 \mathrm{~mm})$ than that of positive control $(5 \mathrm{~mm})$. The potential reason for the antibacterial activity of silver is that AgNPs may attach to the surface of the cell membrane disturbing permeability and respiration functions of the cell
(Kvítek et al. 2005). Smaller AgNPs having the large surface area available for interaction would give more antibacterial effect than the larger AgNPs. It is also possible that AgNPs not only interact with the surface of membrane, but can also penetrate inside the bacteria (Morones et al. 2005). 
Table 1 Antibacterial activity of synthesized silver nanoparticles against some human pathogens

\begin{tabular}{llll}
\hline Species & $\begin{array}{l}\text { Zone of } \\
\text { inhibition in } \\
\mathrm{mm} \text { for } \mathrm{AgNPs} \\
\left(\mathrm{B}_{1}\right)\end{array}$ & $\begin{array}{l}\text { Zone of } \\
\text { inhibition in } \\
\mathrm{mm} \text { for } \mathrm{AgNO}_{3} \\
\left(\mathrm{~B}_{2}\right)\end{array}$ & $\begin{array}{l}\text { Zone of } \\
\text { inhibition in } \mathrm{mm} \\
\text { for positive } \\
\text { control }\end{array}$ \\
\hline P. aeruginosa & 5 & 0 & 7 \\
V. cholera & 5 & 1 & 13 \\
K. pneumoniae & 7 & 3 & 5 \\
S. aureus & 12 & 3 & 6 \\
E. coli & 3 & 2 & 7 \\
S. pneumoniae & 1 & 0 & 8 \\
S. typhi & 7 & 2 & 6 \\
\hline
\end{tabular}

\section{Conclusion}

It has been predicted that the extract of marine seaweed Sargassum wightii is capable of producing Ag nanoparticles extracellularly and these nanoparticles are quite stable in solution due to capping likely by the proteins present in the extract. This is an efficient, eco-friendly and simple process. The $\mathrm{Ag}$ NPs showed potential antibacterial activity against some human pathogens. Therefore, nanoparticles of silver in combination with commercially available antibiotics could be used as an antimicrobial agent after further trials on experimental animals.

Acknowledgments The authors wish to thank Dr. S. Barathan, Professor and Head, Department of Physics, Annamalai University, for providing necessary facilities to carry out this work. We also thank Mr. D. Kannan, NFMTC lab, IIT Madras, for recording HR-TEM. Authors cordially thank Dr. N. Krishnakumar, Assistant Professor, Annamalai University, for his stimulating discussions during the performance of this work.

Open Access This article is distributed under the terms of the Creative Commons Attribution License which permits any use, distribution, and reproduction in any medium, provided the original author(s) and the source are credited.

\section{References}

Alt V, Bechert T, Steinrucke P, Wagener M, Seidel P, Dingeldein E, Domann E, Schnettler R (2004) An in vitro assessment of the antibacterial properties and cytotoxicity of nanoparticulate silver bone cement. Biomaterials 25:4383-4391

Al-Warthan A, Kholoud MM, El-Nour A, Eftaiha A, Ammar RAA (2010) Synthesis and applications of silver nanoparticles. Arabian J Chem 3:135-140

Binupriya AR, Sathishkumar M, Vijayaraghavan K, Yun SI (2010) Bioreduction of trivalent aurum to nano-crystalline gold particles by active and inactive cells and cell-free extract of Aspergillus oryzae var. viridis. J Hazard Mater 177:539-545

Chen H, Hao F, He R, Cui DX (2007) Chemiluminescence of luminol catalyzed by silver nanoparticles. J Colloids Interface Sci 315:158-163
Chou WL, Yu DG, Yang MC (2005) The preparation and characterization of silver-loading cellulose acetate hollow fiber membrane for water treatment. Polym Adv Technol 16:600-607

Elechiguerra JL, Burt JL, Morones JR, Bragado AC, Gao X, Lara HH, Yocaman M (2005) Interaction of silver nanoparticles with HIV1. J Nanobiotechnol 3:6

He ST, Yao JN, Jiang P, Shi DX, Zhang HX, Xie SS, Pang SJ, Gao HJ (2001) Formation of silver nanoparticles and self-assembled twodimensional ordered superlattice. Langmuir 17(5):1571-1575

Jain P, Pradeep T (2005) Potential of silver nanoparticle-coated polyurethane foam as an antibacterial water filter. Biotechnol Bioeng 90:59-63

Jeong SH, Yeo SY, Yi SC (2005) The effect of filler particle size on the antibacterial properties of compounded polymer/silver fibers. J Mater Sci 40:5407-5411

Jin M, Zhang XT, Nishimoto S, Liu ZY, Tryk DA, Emeline AV, Murakami T, Fujishima A (2007) Light-stimulated composition conversion in $\mathrm{TiO}_{2}$-based nanofibers. J Phys Chem C 8:658-665

Kannan RRR, Stirk WA, Van Staden J (2013) Synthesis of silver nanoparticles using the seaweed Codium capitatum P.C. Silva (Chlorophyceae). S Afr J Bot 86:1-4

Karting T, Still F, Reinhaler F (1991) Antimicrobial activity of the essential oil of young pine shoots. J Ethnopharmacol 35:155-157

Kathiresan K, Asmathunisha N (2013) A review on biosynthesis of nanoparticles by marine organisms. Colloids Surf B 103: 283-287

Krishnaraj C, Jagan EG, Ramachandran R, Abirami SM, Mohan N, Kalaichelvan PT (2012) Effect of biologically synthesized silver nanoparticles on Bacopa monnieri (Linn.) Wettst. plant growth metabolism. Process Biochem 47:651-658

Kvítek L, Prucek R, Panáček A, Novotný R, Hrbác J, Zbořil R (2005) The influence of complexing agent concentration on particle size in the process of SERS active silver colloid synthesis. J Mater Chem 15:1099-1105

Lee HY, Park HK, Lee YM, Kim K, Park SB (2007) A practical procedure for producing silver nanocoated fabric and its antibacterial evaluation for biomedical applications. Chem Commun 28:2959-2961

Li S, Shen Y, Xie A, Yu X, Qiu L, Zhang L, Zhang Q (2007) Green synthesis of silver nanoparticles using Capsicum annuиm L. extract. Green Chem 9:852-858

Morones JR, Elechiguerra JL, Camacho A, Holt K, Kouri JB, Ramírez JT, Yacaman MJ (2005) The bactericidal effect of silver nanoparticles. Nanotechnology 16:2346-2353

Nino-Martinez N, Martinez-Castanon GA, Aragon-Pina A, MartinezGutierrez F, Martinez Mendoza JR, Ruiz F (2008) Characterization of silver nanoparticles synthesized on titanium dioxide fine particles. Nanotechnology 19(6):065711/1-065711/8

Rai G, Vyjayanti VN, Dorjsuren D, Simeonov A, Jadhav A, Wilson DM, Maloney DJ (2012) Synthesis, biological evaluation, and structure-activity relationships of a novel class of apurinic/ apyrimidinic endonuclease 1 inhibitors. J Med Chem 55(7): $3101-3112$

Russel AD, Hugo WB (1994) Antimicrobial activity and action of silver. Prog Med Chem 31:351-370

Song JY, Jang HK, Kim BS (2009) Biological synthesis of gold nanoparticles using Magnolia kobus and Diopyros kaki leaf extracts. Process Biochem 44:1133-1138

Susanto H, Feng Y, Ulbricht M (2009) Fouling behavior of aqueous solutions of polyphenolic compounds during ultrafiltration. J Food Eng 91:333-340

Venkatpurwar V, Pokharkar V (2011) Green synthesis of silver nanoparticles using marine polysaccharide: study of in vitro antibacterial activity. Mater Lett 65:999-1002

Williams D (2008) The relationship between biomaterials and nanotechnology. Biomaterials 29:1737 
Xu J, Han X, Liu H, Hu Y (2006) Synthesis and optical properties of silver nanoparticles stabilized by gemini surfactant. Colloids Surf A 273:179-183
Yang W, Yang C, Sun M, Yang F, Ma Y, Zhang Z, Yang X (2009) Green synthesis of nanowire-like Pt nanostructures and their catalytic properties. Talanta 78:557-564 